Research Article

\title{
Evaluation of Basalt Fibers on Wind Turbine Blades through Finite Element Analysis
}

\author{
V. García $(\mathbb{i}$, L. Vargas $(\mathbb{i}$, A. Acuña $(\mathbb{D}$, J. B. Sosa, E. Durazo, R. Ballesteros, and J. Ocampo \\ Universidad Autónoma de Baja California, Facultad de Ingeniería Mexicali, Blvd. Benito Juárez S/N Unidad Universitaria, \\ 21280 Mexicali, BCN, Mexico
}

Correspondence should be addressed to V. García; virginia.garcia@uabc.edu.mx

Received 12 February 2019; Revised 2 April 2019; Accepted 4 April 2019; Published 18 April 2019

Academic Editor: Carlo Santulli

Copyright (c) 2019 V. García et al. This is an open access article distributed under the Creative Commons Attribution License, which permits unrestricted use, distribution, and reproduction in any medium, provided the original work is properly cited.

Here we use finite element analysis to determine the suitability of basalt fiber as a substitute for E-glass in structural applications, which would improve the cost effectiveness of small wind turbine blades. Five NACA (National Advisory Committee for Aeronautics) profiles were evaluated to select the optimum shape for the wind operation conditions. To obtain the wind load pressure distribution over the blade, a computational aerodynamic analysis by CFD (computational fluid dynamics) was performed based on the blade's design and operating conditions. Material properties and mechanical tests were carried out to obtain the fiber volume fraction, density, Young's modulus, shear modulus, and Poisson relation of polymeric matrix composites made using basalt and fiberglass. The obtained wind loads and material properties were used on a FEM (finite element model) analysis to evaluate the structural behavior of the blade under normal and critical operating conditions. Both fibers meet the structural requirements under normal operating conditions. We detected a reduction of $4 \%$ in the blade stress when basalt fibers are used instead of glass fibers, and a reduction of $68 \%$ in the total deformation for a critical load case of $40 \mathrm{~m} / \mathrm{s}$ was obtained when using basalt fibers, which met the structural requirements and maximum power generation required for this wind turbine design.

\section{Introduction}

Wind power is the second strongest growing renewable energy, with an annual growth rate of $34 \%$ [1]. In 2009, it was demonstrated that compared with photovoltaic, geothermal, and hydropower energy, wind power presented the lowest relative greenhouse gas emission and the least water consumption [2]. It is expected that by 2030 , at least $20 \%$ of the United States' energy need will be met by wind farms. To meet the $20 \%$ production goal in the next 15 years, both significant increases in wind turbine installations and an increase in wind turbine operability are required [3].

Although eolic energy has had significant growth in recent years, there are still considerable challenges to improve efficiency and reduce production costs. This is because as the size of the wind turbine rotor increases, the structural requirements also increase. Many authors have proposed various objectives, resolution methods, and algorithms with the goal of optimizing the performance of wind turbines
$[4,5]$. Others have developed multidisciplinary design optimization procedures to compute the annual energy production and wind-based loading trough aerodynamics, structural performance, and durability analysis to determine the minimal blade mass and ensure the structural and durability requirements [6-8]. Some of these models include the blade shape parameters, such as the chord, twist, and relative thickness.

Usually, the obtained model results are compared to experimental data [9] and validated by physical experimental testing on a large scale, and paring FE models and test data showing the blade design can be durable for an extreme gust loading such as $50 \mathrm{~m} / \mathrm{s}$ [10]. To achieve optimal performance, as well as structural and economic feasibility, how the wind turbine blades are manufactured is critical.

The wind turbine manufacturing industry is one of the biggest users of composite materials, primarily found in blades $[11,12]$. Wind turbine blades need high bending stiffness properties because they are exposed to phenomena 
such as fatigue, traction, and flexion. Therefore, the use of composite materials to produce wind turbine blades is controversial because their fatigue properties cannot be accurately predicted $[13,14]$. For this reason, multiple teams have fabricated and characterized wind turbine blades made of glass fiber/vinyl ester composite materials, reporting that dynamic testing of the storage modulus decreases with increase in temperature [15]. For this reason, the manufacturing industry aims to optimize the wind turbines, thereby reducing cost and extending its service life cycle.

For structural optimization, varying the internal geometry to create novel structural configurations is a commonly modified parameter. To investigate the effect of allowing the width of the spar to vary resulted in a 3.5\% reduction in mass, and adding a trailing edge reinforcement reduced mass by an additional $0.6 \%$ with improved structural responses compared to the baseline blade design [16]. It was also possible to optimize wind turbine blades by modifying their shape, stiffness, and stability. However, for this, the conditions to which the wind turbine will be exposed should be known. In an attempt to determine the critical loads (to predict failure modes in large structures and to identify sensitive zones), the mechanical behavior of composite blades has been assessed in previous studies [17]. In optimizing the structural design of the blade, it was found that aerodynamic shell debonding from the adhesive joints is often the initial failure mechanism, causing a progressive collapse of the blade structure. These results were obtained by testing under the flapwise loading for a large full-scale composite wind turbine blade [18].

Few research studies have addressed blade mass as an objective function for weight reduction. Multiple authors have concluded that this dearth of research is principally because the parameterization of the finite element model of the wind turbine blade is not wholly established [19], which thus represents an area of opportunity for future studies. The use of composite materials on wind turbine blades has gained popularity, and it represents a viable alternative for the construction of blades, driven by its lower weight, high stiffness ratio, and good resistance to loads.

The stiffness of a composite material is determined by the stiffness of its fibers and their volume content. Typically, E-glass is used as the main reinforcement in the composites. With increasing volume content of the fibers in unidirectional composites, the stiffness, tensile, and compression strengths increase proportionally, yet at high volume content of fibers (after 65\%), there might be dry areas without resin between fibers and the fatigue strength of the composite reduces [20]. The development of fibers, which are stronger than E-glass fibers, has been the focus of multiple investigations, for example, S-glass (developed in the 1960s) shows $40 \%$ higher tensile and flexural strength and around $20 \%$ higher compressive strength and flexural modulus but is much more expensive than E-glass. S2-glass is a commercial version of S-glass with the same components but different in sizing and certification procedure, but still ten times the cost process of the E-glass [21]. Carbon fibers are considered a promising alternative to glass fibers and show much higher stiffness and lower density, thus allowing the production of thinner, stiffer, and lighter blades. However, these have relatively low damage tolerance, compressive strength, and ultimate strain and are sensitive to the fiber misalignment and waviness, which leads to a strong reduction of compressive and fatigue strength [22]. Due to the high production cost of carbon fibers, there are no prospects of mass application in the near future.

Since $87 \%$ of the 8.7 million ton global fiber-reinforced plastic market is based on E-glass composites, there are opportunities to explore new, low-cost materials [23]. Currently, carbon and glass fibers are mainly used for the production of hybrid blades [24], but few studies have addressed the use of other fibers, such as the basalt fibers, as a reinforcement on the epoxy matrixes [25-27].

When basalt fibers act in conjunction with the polymer (thermoplastic, thermoset, biodegradable, metallic, and concrete matrices), some promising properties have been reported [28]. Since its discovery, basalt fiber as a reinforcement for composites has been mainly used for military operations, such as the fabrication of lightweight and robust material for antiballistic and aerospace applications [29, 30].

This study enables the evaluation of new materials in small wind turbines, comparing basalt and E-glass with the epoxy matrix, confirming that it is worth investigating new types of fibers (other than E-glass) to reduce manufacturing costs, which complements previous work [31]. Since basalt fibers represent an area of opportunity, here we describe a comparative simulation by finite element analysis to determinate if basalt fiber can substitute E-glass composites in wind turbine blades, which represent a potential weight reduction and an easy handle material for manufacturing and reparations.

\section{Materials and Methods}

The main purpose of this study is to evaluate basalt fibers as a substitute for fiberglass in small horizontal axis wind turbines (HAWT). It is assumed that mechanical properties are not reduced if HAWT migrates from fiberglass to basalt fibers. The following methodology was developed to assess the feasibility of switching from fiberglass to basalt fibers. First, the material properties of the basalt fibers composite material must be known. To obtain the material properties, a series of samples were manufactured and tested in a universal tensile machine. Once the mechanical properties were obtained, the ideal power output (IPO) was calculated for the HAWT blades according to the Betz equation, using specific airfoils families and keeping in mind that the aerodynamic profile has a crucial influence on the efficiency of wind turbines. After the IPO was obtained, the blade was designed with the support of a CAD system, which allows for aerodynamic assessment through a CFD software. As a result, the dynamic working pressure is obtained. To calculate the operation parameters and sizing of the wind blade, an iterative evaluation of five NACA airfoils was performed, as well as torque evaluation of the blades at different wind velocities. Finally, as part of a comparative analysis, a structural evaluation was performed to determine the deformation and the von Mises stress. 
2.1. Material Characterization. Five different samples of two different materials (E-glass and basalt fibers) were created for material characterization, at two different orientations with biaxial fibers. Composite materials have different behaviors depending on the plane of work [32], and to obtain a valid FEA result, the material properties must be known. ASTM tests were performed according to the norms D3039, D695-02, D2344, and D790-03 [33-36], which indicates the number of samples that must be tested, as well as the sample manufacturing dimensions. The hand layup method (an open mold technique to fabricate laminated composites) was used to manufacture the samples. Table 1 shows the dimensions of the specimens for material characterization.

The hand layup method consists of dry fabrics that are placed in molds, and epoxy resin is applied to them. Fiber layers are stacked together over the mold, and then a vacuum is generated during the curing cycle to reduce surface finishing problems and remove the resin excess. The negative pressure generated by the vacuum over the laminate fulfills several functions; it removes the trapped air between the layers, compacts the fibers, and provides more uniform laminations, which prevents the orientation of the laminate from changing direction during the curing cycle while also reducing the humidity and optimizing the matrix stress relations along the piece.

For the composite laminate manufacture, fibers with a thickness of $1 \mathrm{~mm}$ were stacked until the thickness established by the corresponding standards [33-36] was achieved. Then, the material layers were impregnated with resin and stacked in a flat mold, and a uniform pressure of 0.88 bar for $1 \mathrm{~h}$ was applied, ultimately achieving a uniform finish. The composition of the laminate samples consists of a volume fraction of $50 \%$ and $45 \%$ of basalt and E-glass, respectively; the remaining percentage is completed with the resin.

The Fiberlay resin used has a dynamic viscosity of 8$13 \mathrm{~Pa} \cdot \mathrm{s}$ and a gel time of $150 \mathrm{~min}$ at room temperature. Modified polyamine for curing epoxy resins was used as the initiator; it provides the cross-linking site with a flash point of $100^{\circ} \mathrm{C}$. Both fibers were impregnated with resin: Pro-Glass Eco 100 RESIN based on bisphenol A/F type benzyl alcohol and pine oils; this resin was used as a thermoset matrix, taking advantage of its various properties, such as impact resistance, water resistance, and less shrinkage during the curing process. The required gel time of the solidification process is around $20 \mathrm{~min}$.

As a result, a flat sheet with a new composite material is obtained. The new flat sheet is cut into different samples (Table 1) to obtain five samples of each material and orientation. For the E-glass and basalt fibers, biaxial fiber orientations were used to create the samples (0/90 degrees and \pm 45 degrees) tested in this study for each of the materials. These materials and orientations were selected because of their wide availability in the market and for allowing a better cohesion between the fiber and the matrix, thereby preventing the absorption of moisture.

The samples were tested in a universal tensile machine with a test speed of $2 \mathrm{~mm} / \mathrm{min}$, with a maximum load
TABLE 1: Specimen dimensions for composite characterization.

\begin{tabular}{lccc}
\hline ASTM standard & Thickness (in) & Width (in) & Length (in) \\
\hline D3039 & 0.25 & 1 & 12 \\
D695-02 & 0.25 & 1 & 12 \\
D790-03 & 0.5 & 1 & 12 \\
D2344 & 0.25 & 0.5 & 12 \\
\hline
\end{tabular}

operation of $44,483 \mathrm{~N}$, which guaranteed the rupture of the fibers (Figure 1). The average results of the 5-sample test with a standard deviation of 2,154.1 are presented in Table 2.

These test results suggest that the fabrication process was successful for both composite materials. The material characterization shows that basalt/epoxy composite has a 23\% higher Young's modulus than E-glass/epoxy, and the shear modulus is $20 \%$ higher for basalt/epoxy than E-glass/epoxy; it is assumed Young's modulus was higher on basalt-epoxy composite due to its individual fiber resistance.

The matrix used for the manufacture of both compounds had an excellent cohesion with both E-glass and basalt fiber. During the mechanical test, it was noticed that composites based on basalt fiber suffered a delamination before reaching the fracture point. In the case of E-glass, the fracture was abrupt (Figure 2). The obtained data from the mechanical characterization are used later as input in the FEM analysis.

2.2. Ideal Power Output. This section describes the mathematical bases to obtain the IPO of a small wind turbine, which is a function of the aerodynamics of the blades of the HAWT. Because the aerodynamic profile has a crucial influence on the efficiency of wind turbines, modern HAWT blades have been designed using specific airfoil families. The blade and the blade tip are designed using a thin airfoil, which generates a high lift to drag ratio. To determine the optimal profile and the IPO, Betz equations are used. Wind velocity is a required parameter when using the Betz equations.

Baja California, México, has an average wind velocity of $10-15 \mathrm{~m} / \mathrm{s}$. These parameters were used to calculate the theoretical optimal profile for this research. The number of blades was selected as three based on the consulted literature [34], which indicates that there is no significant difference in power production between HAWTs of three and four blades, and the manufacturing cost is higher when the number of blades increases.

Next, the blade shape is interpolated between each defined airfoil, and the wind turbine radius is calculated as a length of $R=5 \mathrm{~m}$, with a tip speed ratio of $\lambda=7$. The selection of the speed is generally due to the frequency of operation of the torque converter.

According to Betz, to extract the maximum energy from the wind, there is an optimum reduction of wind speed. The power of wind is extracted by the wind deceleration caused by the wind turbine, but it is clear that the speed cannot be reduced to zero. The power and torque are given by 


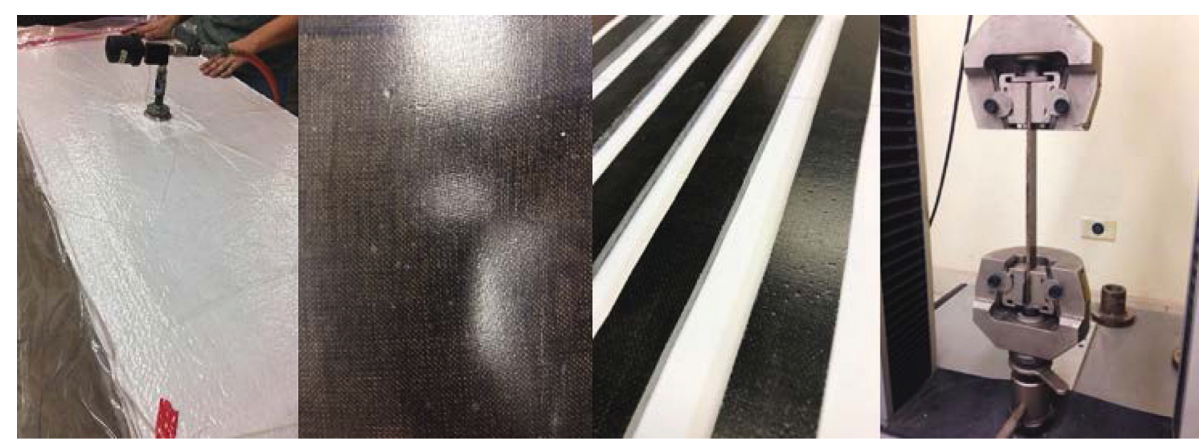

FIgURE 1: Fabrication and testing of composite materials for a wind turbine blade.

TABle 2: Material properties of the composite characterization of basalt/epoxy (B-E) and E-glass/epoxy (EG-E).

\begin{tabular}{cccccccccc}
\hline \multicolumn{10}{c}{ Properties } \\
\hline Composite & $E_{1}(\mathrm{GPa})$ & $E_{2}(\mathrm{GPa})$ & $E_{3}(\mathrm{GPa})$ & $G_{12}(\mathrm{GPa})$ & $G_{13}(\mathrm{GPa})$ & $G_{23}(\mathrm{GPa})$ & $v_{12}$ & $v_{13}$ & $v_{23}$ \\
B-E & 45.82 & 45.82 & 7.1 & 11.34 & 2.7 & 2.7 & 0.04 & 0.305 & 0.3 \\
EG-E & 35 & 9 & 9 & 4.7 & 3.5 & 4.7 & 0.28 & 0.4 & 0.25 \\
\hline
\end{tabular}

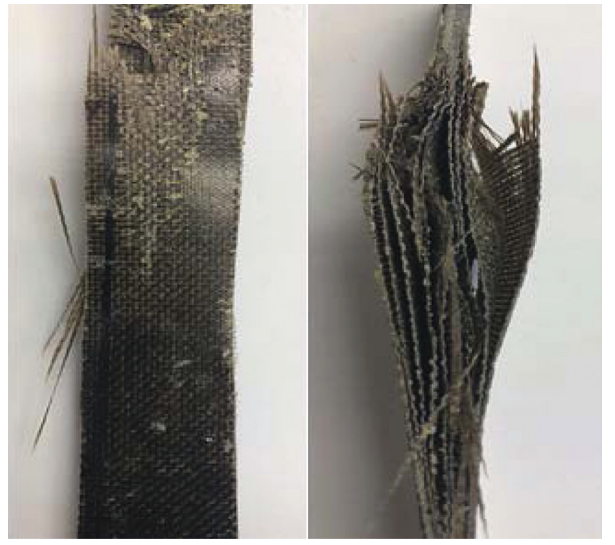

(a)

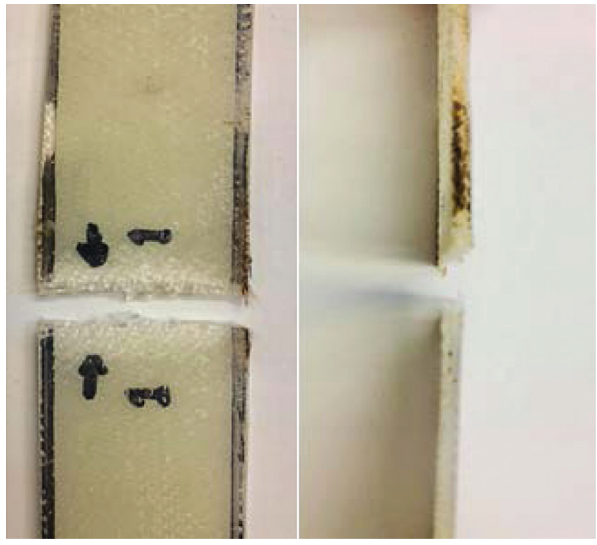

(b)

FIGURE 2: Basalt and glass fiber specimens after the norm ASTM D3039 test. (a) Basalt with fiber orientations 0/90. (b) Glass fiber with fiber orientations $0 / 90$.

$$
\begin{aligned}
& P=\frac{1}{2} \rho v_{1}^{3} A C_{\mathrm{P}}, \\
& T=\frac{1}{2} \rho v_{1}^{2} A C_{\mathrm{T}},
\end{aligned}
$$

where $C_{\mathrm{p}}$ is power coefficient, $\rho$ is the density of air, $v$ is the wind velocity, and $A$ is the swept area. Using the Betz formulation, $C_{\mathrm{p}}$ has an optimum at $16 / 27$, at an axial interference factor of $1 / 3$. The power production can be determined as

$$
P_{\text {Betz }}=C_{\text {PBetz }} \frac{1}{2} \rho v_{1}^{3} A .
$$

The Betz methodology uses several relationships between the pitch angle $\beta$, chord length $c$ of the airfoil section that is a part of the wind turbine blade (shown in Figure 3), and the aerodynamic coefficients to calculate the blade shape.

Therefore, the proper selection of the airfoil section is an important step in the methodology. Five standard airfoil sections are considered in this work: NACA 24112, NACA
22112, NACA 25112, NACA 4412, and NACA 64212, which are the most suitable profiles for wind turbine applications. The profile selection was driven by the GR (glide ratio) high values listed in Table 3.

2.3. Blade Design. To obtain the optimal design of the wind turbine blade, the work presented by several authors [37-40] was used as a starting point, which provides an overview of the commonly used models, techniques, tools, and experimental approaches applied to increase the efficiency of the wind turbines, with particular emphasis on approaches used to design wind turbine blades.

All of the wind turbine blade geometries were created by NURBS surfaces using the discrete $(x, y, z)$ values calculated by the Betz methodology. To achieve smooth surface transitions, the slope transition between the root-blade-tip surfaces was preserved as continuous. To obtain the CAD models, the implementation was performed in a mathematical processor and then translated by macros to a standard CAD system. 


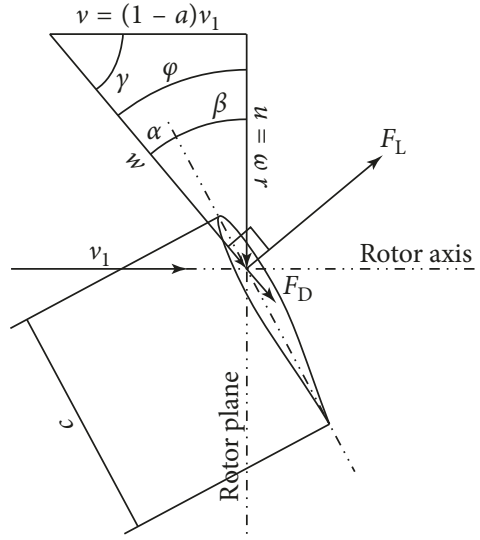

(a)

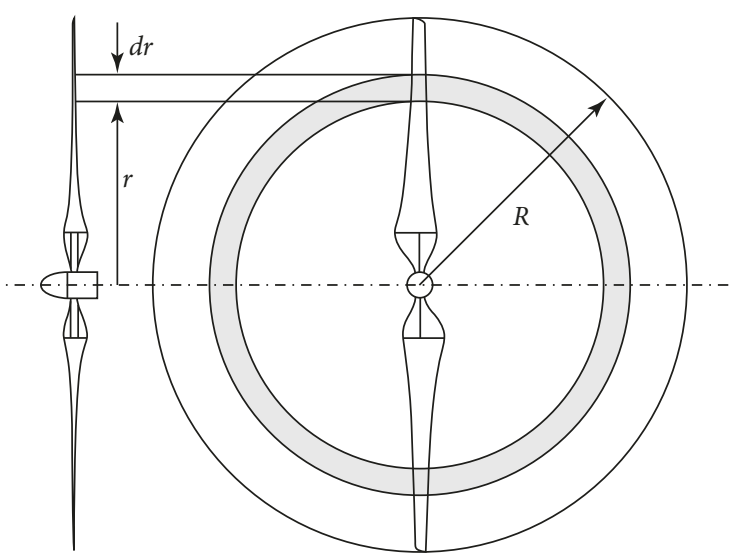

(b)

FIGURE 3: The main geometric features of the wind turbine.

TABLE 3: Selection of NACA airfoils based on GR $\left(C_{\mathrm{L}} / C_{\mathrm{D}}\right)$ for aerodynamic evaluation.

\begin{tabular}{lc}
\hline NACA shape & GR \\
\hline 64212 & 90 \\
22112 & 90 \\
24112 & 105 \\
25112 & 110 \\
4412 & 120 \\
\hline
\end{tabular}

The final wind turbine geometry used for the FEA simulation is shown in Figure 4(a). The blade has to be twisted around the elastic axis since, according to the calculations of Betz methodology, the angle $\beta$ must have a variation. The position of the elastic center and the shape of the wind blade can be changed by modifying the position of spares. At the tip of the turbine, the blade lift force losses are introduced, similar to those found in wind tip vortices on turbine blades. The above effect can be reduced by adding a triangular shape at the end of the blade. The tip shape selected is a straight type due to its manufacturing facility; Figure 4(b) shows the tip correction used for the NACA 4412 airfoil. The blade profile parameters have a longitude of $4.0438 \mathrm{~m}$, which starts in a cylindrical shape at the base and then transitions to an airfoil NACA 4412 profile, with a maximum tip speed ratio of $\lambda=7$.

The orientation of the fibers proposed for the manufacture of the blade is shown in Table 4; with the purpose of having a simple manufacture for low capacity wind turbine blades, the fiber layers are on the same direction until reaching a thickness of $0.25 \mathrm{in}$.

2.4. CFD Simulation. For the CFD simulations, an unstructured tetrahedral mesh was used; the averaged mesh size of all discretized turbine geometries was 3,077,000 cells, and a mesh size function was attached to the blade walls to capture the boundary layer phenomena. Figure 5 shows the grid detail near the blade wall. The computational domain length was extended 1.2R towards both the front and rear $x$ - directions. The domain dimensions are displayed in Figure 6 . The mesh independence study shows that the convergence is good and the power coefficient as well the wind load pressure reaches stable behavior when the grid values are greater than 2,000,000, and the first layer of the grid height is $y<0.45 \mathrm{~mm} ; y+<170 \mathrm{~mm}$. All turbine discretization contains greater grid numbers than 2,500,000; therefore, the merge convergence study has the target function on the power coefficient, which is directly related with the torque and the wind load; the mesh convergence study is focused on the average mesh size and the mesh boundary layer.

To achieve considerable time reductions in simulations, a periodic boundary condition is assumed. The free stream velocity in the $x$-direction is applied on the blue surfaces. The atmosphere condition is set for the outlet surface. The blade surfaces were modeled as wall boundaries with the no-slip condition. A rotational reference frame considers a wind turbine angular velocity of $14 \mathrm{rad} / \mathrm{s}$.

The flow field solution is based on an incompressible RANS model, the SST $\kappa-\omega$ turbulence model was selected to solve the steady flow, and a commercial package solver was used to implement the solution (Fluent 17.2). All of the wind turbines were simulated on a 2 to $30 \mathrm{~m} / \mathrm{s}$ free stream wind velocity range using steps of $2 \mathrm{~m} / \mathrm{s}$ (and $40 \mathrm{~m} / \mathrm{s}$ to obtain the wind load pressure distribution). The 80 simulation results are displayed in Figures 7-10.

\section{Results and Discussions}

3.1. CFD Results and Discussions. By CFD simulation, we found that under normal operating conditions (average wind speed, $12 \mathrm{~m} / \mathrm{s}$; maximum wind speed $40 \mathrm{~m} / \mathrm{s}$ ), the maximum pressure was $3.47 \times 10^{3} \mathrm{~Pa}$ and the minimum pressure was $9.81 \mathrm{~Pa}$ (Figure 11(a)). The maximum pressure is located on the borders of the blade, specifically on the lower zone. For the critical operation point of $40 \mathrm{~m} / \mathrm{s}$ (Figure 11(b)), the maximum pressure is located along the blade with a value of $1.24 \times 10^{4} \mathrm{~Pa}$, and the minimum pressure is located on the turbine hub $(7.47 \mathrm{~Pa})$. Since the dynamic pressure depends on the speed squared, it is to be 


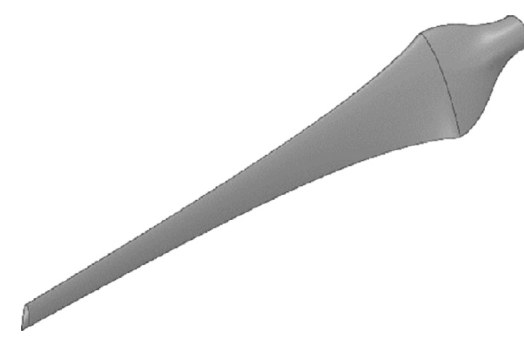

(a)

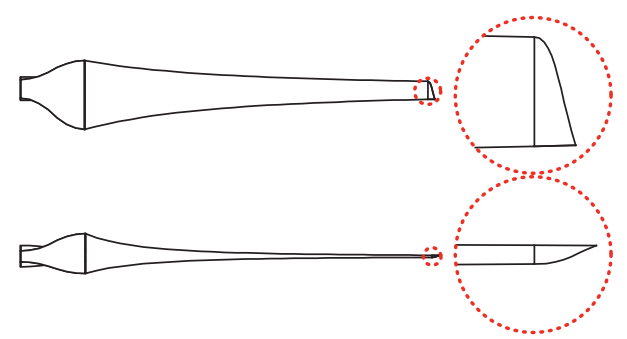

(b)

Figure 4: (a) Rotor blade design based on the NACA 4412. (b) Blade thin tip.

TABle 4: Composite fiber orientation for basalt and E-glass.

\begin{tabular}{lc}
\hline Laminates & Plies \\
\hline Bidirectional fibers & {$[0 / 90] 11$ plies } \\
\hline
\end{tabular}

expected that as the speed increases, the dynamic pressure to which the blade is exposed also increases.

From this point forward, it is possible to calculate the power and thrust coefficient. The nondimensional values that quantify wind turbine efficiency, called coefficient of power $\left(C_{\mathrm{p}}\right)$ and thrust $\left(C_{\mathrm{Tr}}\right)$, are the ratios of the power and thrust extracted from the wind to the total power in the wind crossing the turbine area. These values are essential for determining the final power output of the wind turbine and the thrust to which the profile will be submitted. Figure 8 corresponds to the CFD results of the power coefficient at different tip speed ratios $(\lambda)$ and wind velocities $(V)$.

Considering that the Betz limit determines the maximum theoretical value of the coefficient (16/27) between the tip speed ratio range of zero to four, all profiles express a similar behavior, where the power coefficient increases as the tip speed ratio increases. In this range, the power coefficient has a value close to 0.3 . For the airfoils 4412 and 64212, we found that the best performance is where $\lambda$ has a value of 6 . However, the performance of profile 4412 is superior to 64212 (by 20\%). Comparing profiles 24112 and 25112, their yield curves are similar, so its maximum point is at $\lambda=5$, where the value of the power coefficient is 0.3 . The 22112 profile performed worst, with a coefficient close to 0.26 and $35 \%$ less than the airfoil maximum performance.

Figure 8 shows the optimum speed ranges between 10 and $15 \mathrm{~m} / \mathrm{s}$ for optimal performance; after passing this point, the power coefficient starts to decrease dramatically for all of the airfoils. The profiles with better behavior are NACA 4412 and 64212; their optimum performance was reached when the wind speed was $12 \mathrm{~m} / \mathrm{s}$ and $14 \mathrm{~m} / \mathrm{s}$, respectively. For the remaining profiles, there is an optimal point of operation when the wind speed reaches $15 \mathrm{~m} / \mathrm{s}$. Furthermore, we observed that while all profiles are subjected to high wind speeds between the ranges of 23 to $30 \mathrm{~m} / \mathrm{s}$, the power coefficient is practically the same around 0.1 , having losses of $82 \%$ when compared with the ideal coefficient of Betz theory.

Figure 9 shows the thrust results for all of the turbines; although the profiles have similar performance in the thrust coefficient, the maximum points of operation differ from the power coefficient. Figure 9(a) shows that the maximum point of operation is given by the airfoil 4412 with a value of 0.18 when the tip speed ratio has a value of $\lambda=7$, followed by profile 64212 with a maximum value of 0.15 when $\lambda=6$. In the remaining profiles, the optimum performance is located at a tip speed ratio of $\lambda=5$, with $C_{\operatorname{Tr}}$ values close to 0.13 ; once the tip speed ratio passes the optimum point of operation, the performance decreases, reaching a point where the difference between the profile with better yield and the rest is doubled. Figure 9(b) shows that the optimum point was found when the wind velocity reaches $10 \mathrm{~m} / \mathrm{s}$; for the remaining airfoils, the optimum is near $12 \mathrm{~m} / \mathrm{s}$. Also, at higher wind speeds, between 20 and $30 \mathrm{~m} / \mathrm{s}$, the thrust coefficient remains stable for the different airfoils.

The wind turbine power output is calculated by equation (3), where $P$ is the power, $T$ is the torque, and $w$ is the angular velocity of the turbine blades:

$$
P=T \omega .
$$

Therefore, it was necessary to evaluate the torque of the blade at different wind velocities. Figure 10 shows the torque evaluation from a range of 0 to $30 \mathrm{~m} / \mathrm{s}$. In this graph, as the wind speed increases, the torque increased in all profiles within the range of 2 to $19 \mathrm{~m} / \mathrm{s}$, the profiles are subject to sudden changes as the speed increases. After this point, the torque in all profiles remained relatively constant; the airfoil with higher torque was 4412 , obtaining a value of $2600 \mathrm{Nm}$ at a wind velocity of $25 \mathrm{~m} / \mathrm{s}$; the maximum yield of the airfoil 25112 is when the wind speed reaches $26 \mathrm{~m} / \mathrm{s}$ but remains $7 \%$ below the maximum torque value. The lowest result was given by the airfoil 22112 with a torque of $1400 \mathrm{Nm}$ (being 30\% below the maximum value). As a result, the profile with the best aerodynamic performance was NACA 4412 (the highest torque values were obtained using this profile). This finding supports the previous curves of $C_{\mathrm{p}}$ for this turbine operating range.

It is also noticed that at the range of velocities of 10 to 20 , the power production outcome is similar for all airfoils and it is in the ranges of 10 to $20 \mathrm{~kW}$. However, when this equilibrium point is passed, power production is destabilized after $20 \mathrm{~m} / \mathrm{s}$, showing marked variation in all profiles (Figure 11). As a final result, the profile that presents the optimum performance is 4412 , having a maximum power output of $24 \mathrm{~kW}$ for each blade at a wind speed of $20 \mathrm{~m} / \mathrm{s}$.

For this section, based on the results obtained in the previous graphs, NACA 4412 performed best, which is in line with our torque and power coefficient data, as well as the corresponding wind load. 


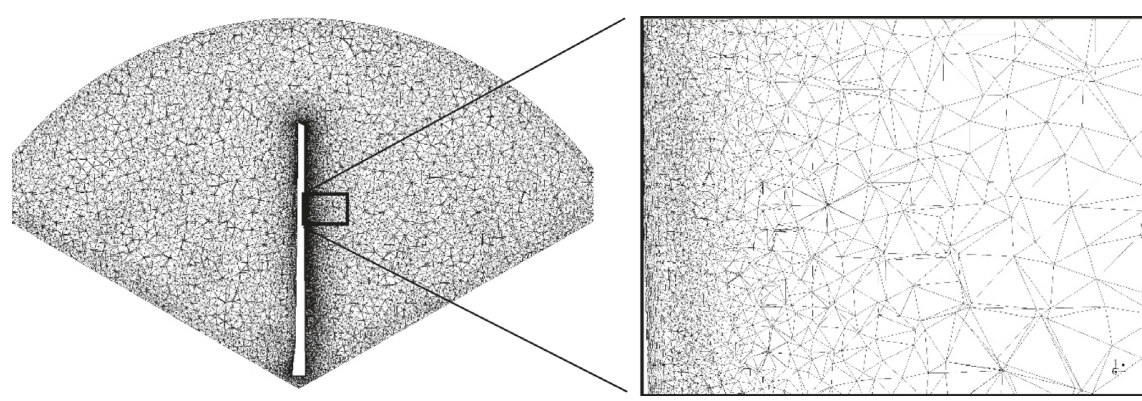

FIgURE 5: Wind turbine spatial discretization (mesh).

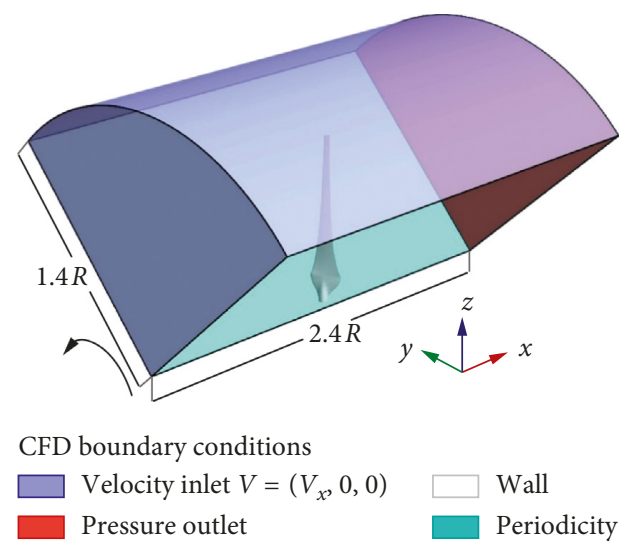

FIGURE 6: Fluid volume for aerodynamic simulation and boundary conditions used on CFD simulation.

3.2. FEM Results and Discussions. To investigate the suitability of basalt as a material for the construction of wind turbine blades, we compared the performance of basalt and fiberglass under normal (wind speed of $12 \mathrm{~m} / \mathrm{s}$ ) and critical (wind speed of $40 \mathrm{~m} / \mathrm{s}$ ) conditions. Based on our findings, we propose that basalt is suitable for use in wind turbine blades.

In the structural simulation, the blade is considered as hollow, without core or rib reinforcements. The imposed loads were the wind load given by the pressure distribution over the blade surface and the centrifugal load given by the angular velocity of $14 \mathrm{rad} / \mathrm{s}$ about the $x$-axis. The pressure distribution was obtained by the CFD simulation. Considering the worst operation condition $V=(40,0,0) \mathrm{m} / \mathrm{s}$, a fixed support is considered on the lower circular edge, simulating the root-hub embedment. Figure 12 shows the boundary conditions.

For the structural evaluation, deformation and the von Mises stress are assessed and obtained from the CAD and FEM analysis, together with the conditions obtained in Section 2.2. The blade is considered an orthotropic composite material (constant thickness of $0.5 \mathrm{in}$ ). The considered material properties are listed in Table 1. The element used was the shell element. The static, linear, structural solver was selected.

To test the structural behavior of the blade at different conditions, a turbulent wind flow was simulated toward the $x$-direction at $12 \mathrm{~m} / \mathrm{s}$ and $40 \mathrm{~m} / \mathrm{s}$. This incoming flow makes the blade route at an angular velocity of $14 \mathrm{rad} / \mathrm{s}$ about the $z$ axis (the blade is thus spinning clockwise when observed
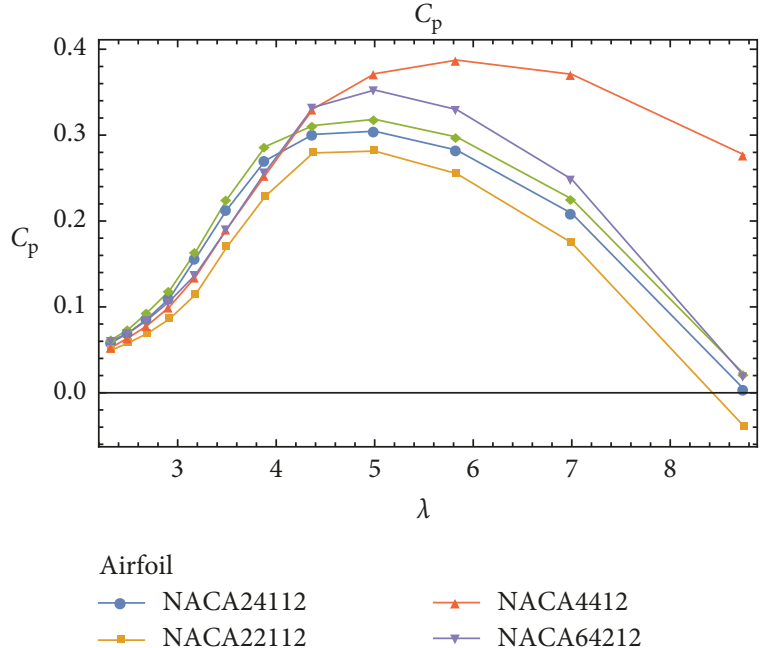

$\because$ NACA25112

(a)

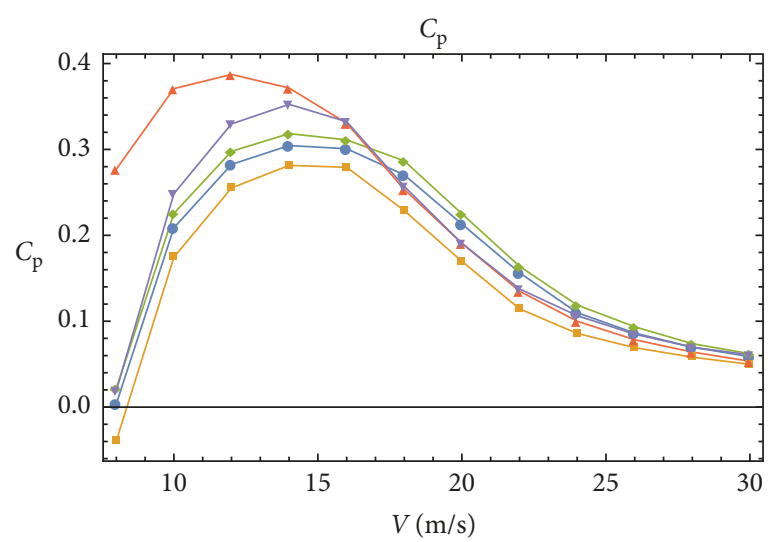

Airfoil

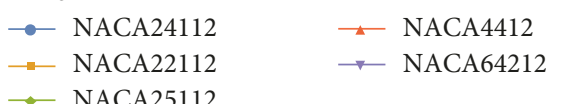

(b)

FIgURE 7: Evaluation of power coefficient $\left(C_{\mathrm{p}}\right)$ vs. the tip speed ratio and wind velocity.

from the front). For the FEA simulation, a new material must be created in the software as an orthotropic material given as the properties calculated before as density, Young's modulus, shear modulus, and Poisson relation. Once the 

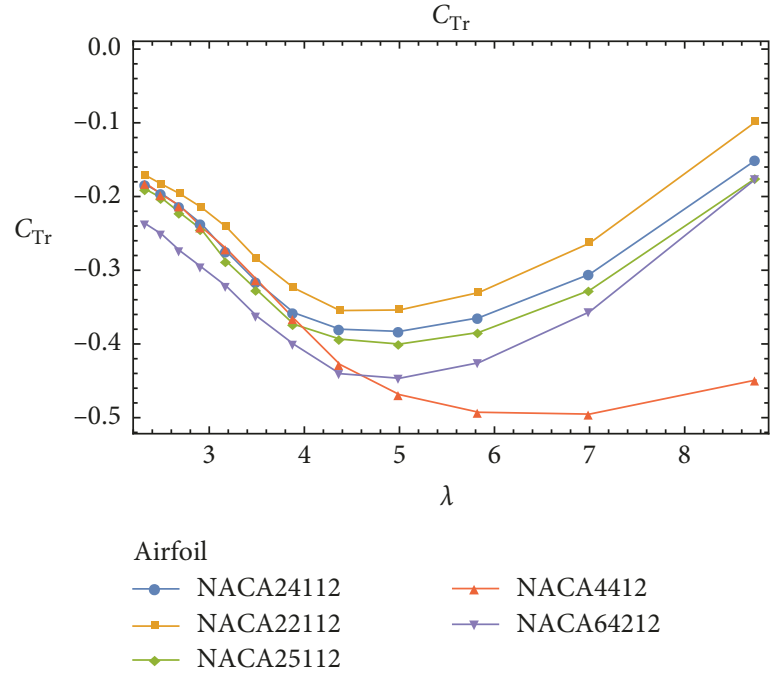
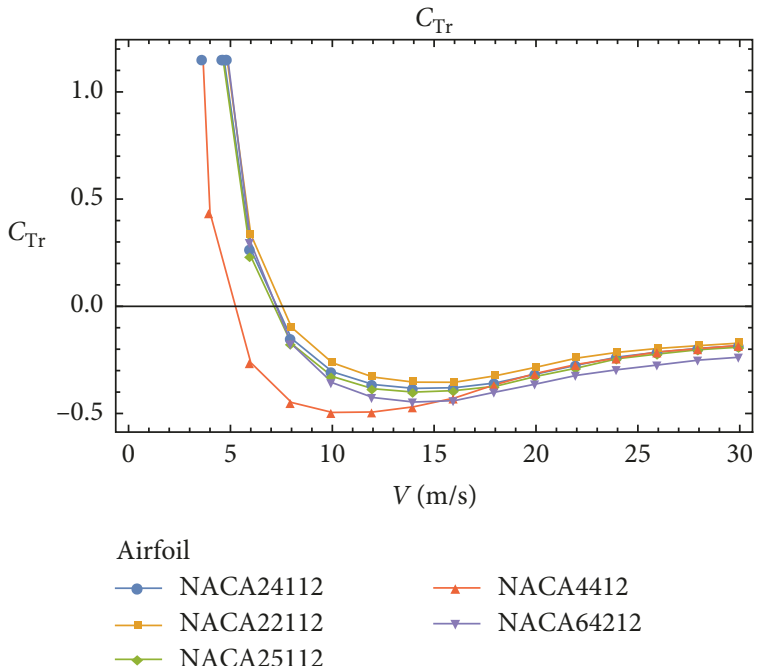

(b)

Figure 8: Curves $C_{\operatorname{Tr}}$ vs. $(\lambda)$ and $C_{\operatorname{Tr}}$ vs. V.

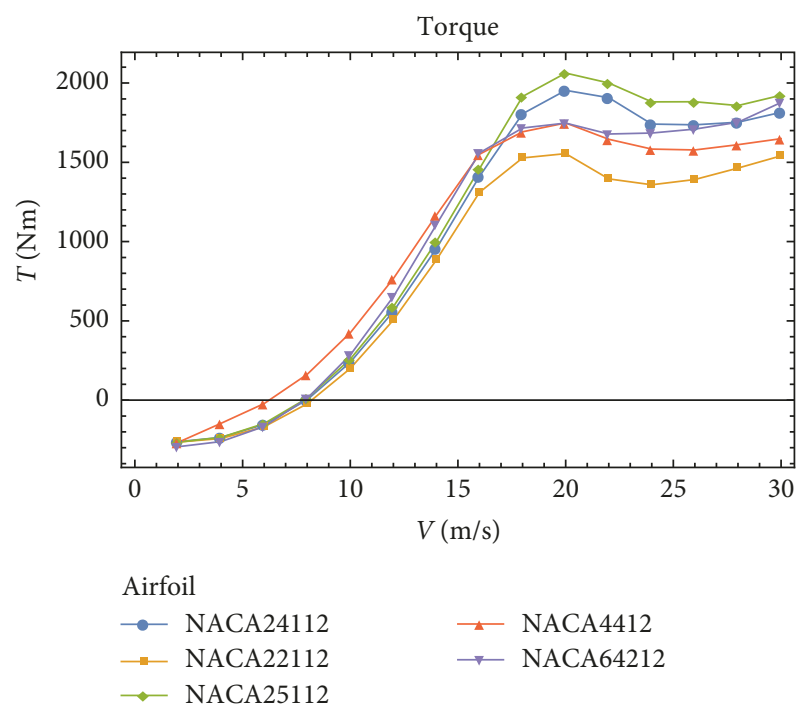

Figure 9: Torque evaluation of NACA profiles at different wind velocities.

material was created, the body is meshed, and the computational domain was discretized 44592 nodes. The structural analysis was performed using shell elements (44921); the boundary conditions must consider a fixed support on the circular section of the rotor blade simulating the embedment. In the case of the structural loads, the results obtained from the aerodynamic simulation were imported from the CFD results to the FEM static structural analysis. For the structural evaluation, the stress was evaluated by von Mises in the orthotropic plane on which the fiber is oriented, and this is bidirectional fiber on 0/90.

The structural analysis shows the results obtained at normal and critical conditions, to guarantee safe operation of the wind turbine. Table 5 shows the results obtained for the typical operation condition E-glass/epoxy composite with equivalent stress of $3.78 \times 10^{6} \mathrm{~Pa}$ and a total deformation of
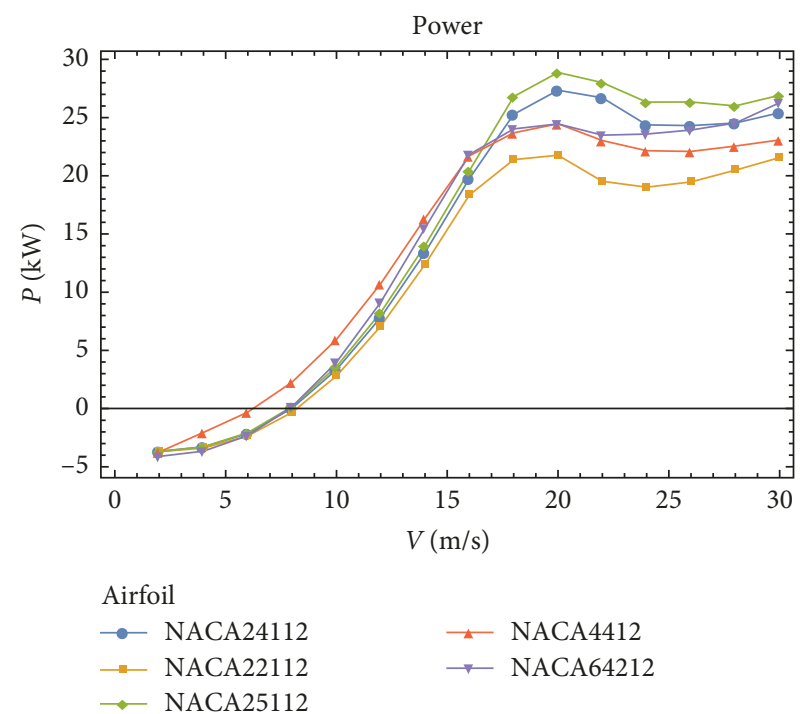

Figure 10: Power evaluation of the wind turbine NACA airfoils at different wind speeds.

$0.5209 \mathrm{~m}$; in case of the critical operating condition, the results show an equivalent stress of $4.72 \times 10^{7} \mathrm{~Pa}$ and a total deformation of $0.8035 \mathrm{~m}$.

In the case of the compound made with basalt fiber and epoxy resin, we found that for a normal operating condition, the equivalent stress has a value of $3.14 \times 10^{6} \mathrm{~Pa}$ and a total deformation of $0.0161 \mathrm{~m}$. Comparing this result with the compound E-glass base shows that there was a $16 \%$ reduction in effort and a $96 \%$ reduction in total deformation. Table 5 shows the results obtained by the compound based on basalt fiber.

For the critical condition of operation, the basalt fiber obtained an equivalent stress of $4.55 \times 10^{7} \mathrm{~Pa}$ and a reduction of $4 \%$, while the total deformation was reduced by $68 \%$. Figure 13 shows the total deformation that corresponds to 


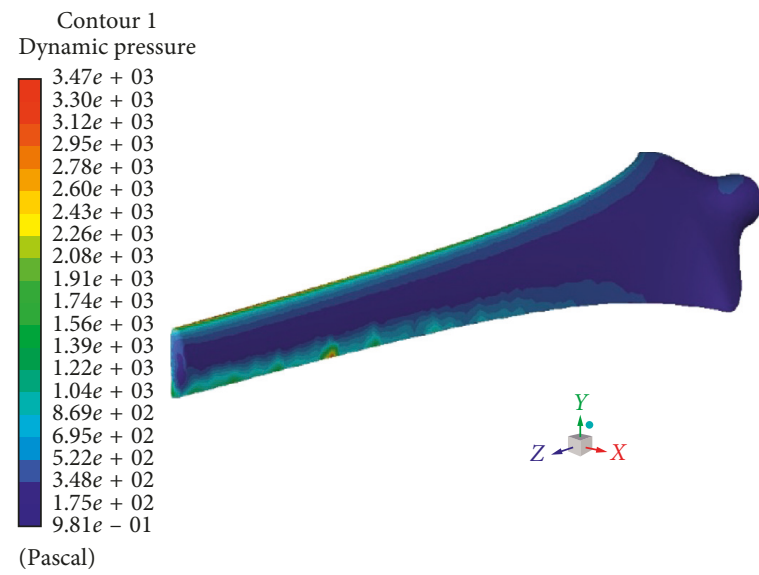

(a)

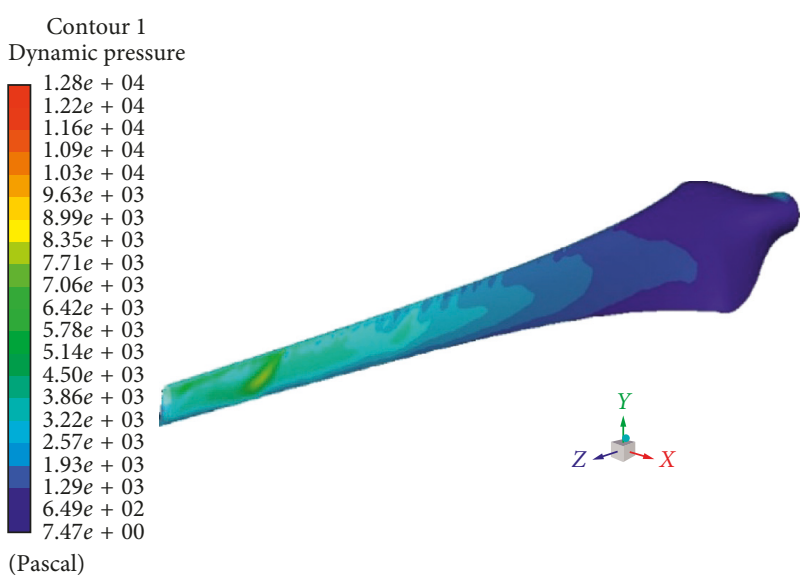

(b)

Figure 11: Pressure contours over the blade surface. (a). Contour pressure for $12 \mathrm{~m} / \mathrm{s}$. (b). Contour pressure for $40 \mathrm{~m} / \mathrm{s}$.

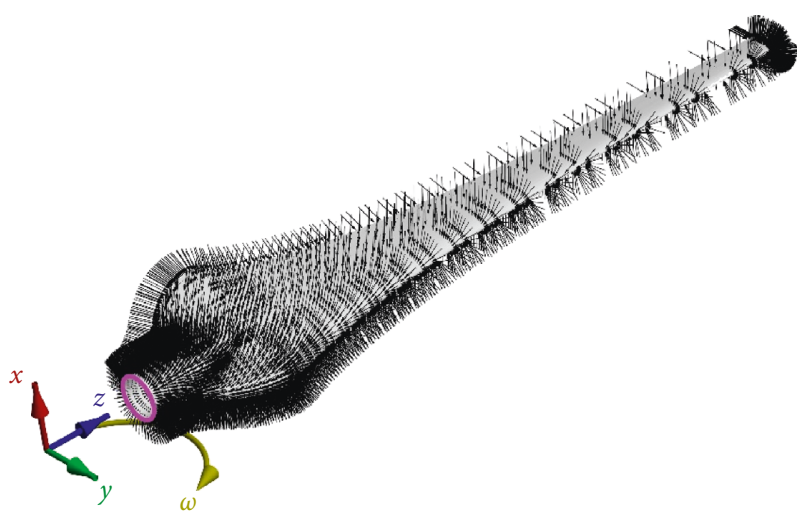

FEM boundary conditions

WUW Wh Wind load pressure

— Fixed support

$\frown$ Angular velocity

FIGURE 12: FEM boundary conditions.

TABLE 5: Structural results for the basalt-epoxy and E-glass-epoxy wind blade composite.

\begin{tabular}{lccc}
\hline Wind velocity & Results & E-glass/epoxy & Basalt/epoxy \\
\hline \multirow{2}{*}{$12 \mathrm{~m} / \mathrm{s}$} & Equivalent stress & $3.78 \times 10^{6} \mathrm{~Pa}$ & $3.14 \times 10^{6} \mathrm{~Pa}$ \\
& Total deformation & $0.5209 \mathrm{~m}$ & $0.0161 \mathrm{~m}$ \\
\hline \multirow{2}{*}{$40 \mathrm{~m} / \mathrm{s}$} & Equivalent stress & $4.72 \times 10^{7} \mathrm{~Pa}$ & $4.55 \times 10^{7} \mathrm{~Pa}$ \\
& Total deformation & $0.8035 \mathrm{~m}$ & $0.2555 \mathrm{~m}$ \\
\hline
\end{tabular}

the glass fiber and basalt, and the total displacement affects $3 / 4$ parts of the whole of the blade, obtaining the minimum deformation of $0.0892 \mathrm{~m}$.

In the results of the total deformation for the basaltepoxy blade, it can be seen that the maximum deformation agrees with the point where the blade is exposed to the maximum load, obtaining $0.2552 \mathrm{~m}$. The minimum deformation appears over two-thirds of the wind blade, with a value of $0.0283 \mathrm{~m}$, and the blade does not suffer from plastic deformation, which means the composite material can be used as a substitute for E-glass in the fabrication of low capacity wind turbine blades.

In the case of the von Mises stress (3D and orthotropic plane, Figures 14 and 15, respectively) for the basalt-epoxy composite, the maximum stress is identified in two zones that could be considered critical, the first one being close to the shaft and the second one in the central zone of the blade due to the pressure contours generated by the wind impacting in the turbine blade. Comparing the deformation results of both compounds, we found that the basalt fiberbased compound is positive for a substitution of conventional material due to a reduction in deformation of up to $96 \%$.

\section{Conclusions}

In this work, a comparative analysis of the E-glass fibers used in the manufacture of wind turbine blades was made to contrast their mechanical properties with basalt fibers. To determine the optimum profile and achieve adequate production for a low capacity wind turbine, an aerodynamic evaluation was carried out. To define the mechanical properties, different manufacturing methods were evaluated to achieve the best surface finish and the best union between the reinforcement and the matrix. Once the blade design was established, to know the normal and critical conditions on the wind turbine blade, a comparison of the pressure contours was made through an aerodynamic simulation. Then, though structural analysis using the finite element method, we tested if the proposed material could viably replace the conventional material.

Due the manufacturing process used, it was possible to identify basalt fibers are high-strength, high-modulus fibers, with excellent shock resistance, high-temperature resistance, and excellent corrosion properties. Basalt fibers are easy to handle and do not need specialized processing equipment, can be recycled, and are compatible with many resins as epoxy. With this work, it was possible to identify parameters of fiber content, fabric architecture, and percent material that have a wide impact when systematically varied. 


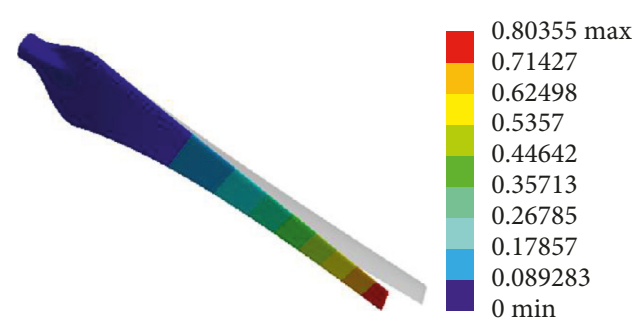

(a)

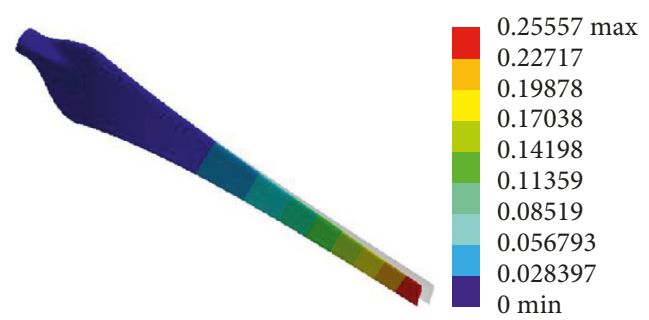

(b)

Figure 13: Total deformation for E-glass-epoxy and basalt-epoxy at $40 \mathrm{~m} / \mathrm{s}$.

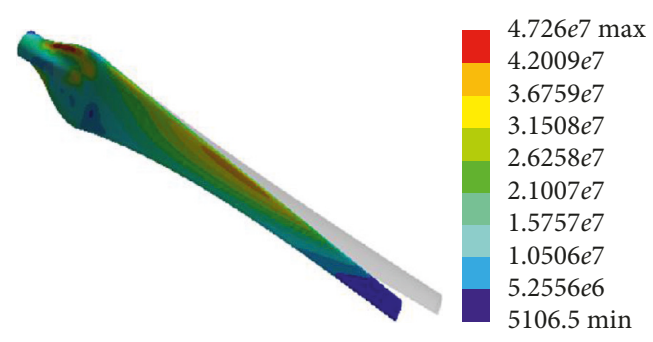

(a)

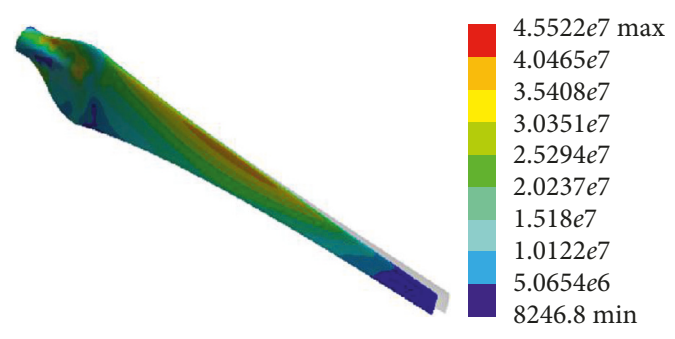

(b)

Figure 14: von Mises stress for E-glass-epoxy and basalt-epoxy at $40 \mathrm{~m} / \mathrm{s}$.

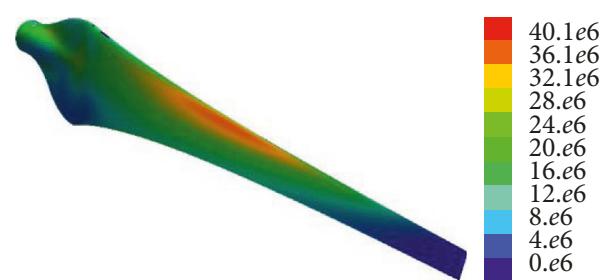

(a)

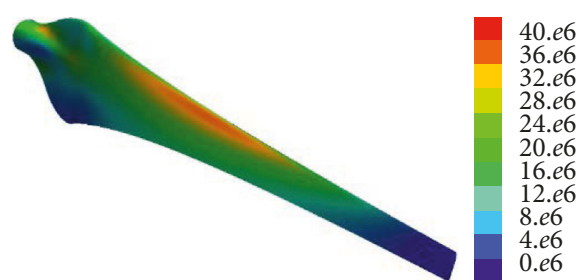

(b)

Figure 15: $\sigma_{\mathrm{VM}}=\sqrt{\sigma_{\mathrm{L}}^{2}+\sigma_{\mathrm{T}}^{2}-\sigma_{\mathrm{L}} \sigma_{\mathrm{T}}+3 \tau_{\mathrm{LT}}}$, von Mises stress evaluation for E-glass-epoxy and basalt-epoxy at $40 \mathrm{~m} / \mathrm{s}$.

The aerodynamic CFD analysis allows optimal wind blade selection and to obtain the wind load pressure distribution needed to predict the structural behavior of a small wind turbine under real conditions in Baja California, México.

Based on the obtained FEM results, basalt-epoxy blades satisfy the design and structural integrity requirements for a wind turbine of $35 \mathrm{~kW}$ of energy production, with a blade radius of $5 \mathrm{~m}$ long, under normal and critical case loading conditions, validating that basalt fibers are a viable alternative to substitute E-glass fibers. The lower density of basalt fibers enables component weight savings. It was found that the basalt-epoxy blade is $2 \%$ lighter than the E-glass-epoxy blade. The basalt/epoxy composite has a $23 \%$ higher Young's modulus than E-glass/epoxy, and for the shear modulus, the results show that basalt/epoxy is $20 \%$ higher than E-glass/ epoxy.

For the maximum wind conditions assessed on this study, the power output for the NACA 4412 can reach $35 \mathrm{~kW}$, with a minimum power output for the proposed HAWT for each blade of $2 \mathrm{~kW}$, with a wind velocity of $8 \mathrm{~m} / \mathrm{s}$ for each wind blade. The total deformation of the wind turbine blade was reduced by $68 \%$; this can guide future studies evaluating basalt fibers in larger wind turbine blades and significantly reduce manufacturing costs-basalt fiber is cheaper than carbon fiber.

\section{Data Availability}

The experimental and simulation data used to support the findings of this study are included within the article.

\section{Conflicts of Interest}

The authors declare that they have no conflicts of interest.

\section{References}

[1] A. A. Bazmi and G. Zahedi, “Sustainable energy systems: role of optimization modeling techniques in power generation and supply-a review," Renewable and Sustainable Energy Reviews, vol. 15, no. 8, pp. 3480-3500, 2011.

[2] A. Evans, V. Strezov, and T. J. Evans, "Assessment of sustainability indicators for renewable energy technologies," 
Renewable and Sustainable Energy Reviews, vol. 13, no. 5, pp. 1082-1088, 2009.

[3] S. Lindenberg, B. Smith, and K. O'Dell, "20\% wind energy by 2030," National renewable energy laboratory (NREL), US Department of Energy, renewable energy consulting services, energetics incorporated, Palo Alto, CA, USA, Technical Report, 2008.

[4] S. E. Mouhsine, K. Oukassou, M. M. Ichenial, B. Kharbouch, and A. Hajraoui, "Aerodynamics and structural analysis of wind turbine blade," Procedia Manufacturing, vol. 22, pp. 747-756, 2018.

[5] J. X. V. Neto, E. J. G. Junior, S. R. Moreno, H. V. H. Ayala, V. C. Mariani, and L. D. S. Coelho, "Wind turbine blade geometry design based on multi-objective optimization using metaheuristics," Energy, vol. 162, pp. 645-658, 2018.

[6] M. Grujicic, G. Arakere, B. Pandurangan, V. Sellappan, A. Vallejo, and M. Ozen, "Multidisciplinary design optimization for glass-fiber epoxy-matrix composite $5 \mathrm{MW}$ horizontal-axis wind-turbine blades," Journal of Materials Engineering and Performance, vol. 19, no. 8, pp. 1116-1127, 2010.

[7] M. Jureczko, M. Pawlak, and A. Mężyk, "Optimisation of wind turbine blades," Journal of Materials Processing Technology, vol. 167, no. 2-3, pp. 463-471, 2005.

[8] J. Chen, Q. Wang, W. Z. Shen, X. Pang, S. Li, and X. Guo, "Structural optimization study of composite wind turbine blade," Materials \& Design, vol. 46, pp. 247-255, 2013.

[9] W. Xudong, W. Z. Shen, W. J. Zhu, J. N. Sørensen, and C. Jin, "Shape optimization of wind turbine blades," Wind Energy, vol. 12, no. 8, pp. 781-803, 2009.

[10] E. M. Fagan, M. Flanagan, S. B. Leen, T. Flanagan, A. Doyle, and J. Goggins, "Physical experimental static testing and structural design optimisation for a composite wind turbine blade," Composite Structures, vol. 164, pp. 90-103, 2017.

[11] L. Mishnaevsky, "Composite materials for wind energy applications: micromechanical modeling and future directions," Computational Mechanics, vol. 50, no. 2, pp. 195-207, 2012.

[12] M. Nachtane, M. Tarfaoui, D. Saifaoui, A. El Moumen, O. H. Hassoon, and H. Benyahia, "Evaluation of durability of composite materials applied to renewable marine energy: case of ducted tidal turbine," Energy Reports, vol. 4, pp. 31-40, 2018.

[13] L. S. Phoenix, "Modeling the statical lifetime of glass fiber/ polymer matrix composites in tension," Composite Structures, vol. 48, no. 1-3, pp. 19-29, 2000.

[14] R. Talreja, "Damage and fatigue in composites-a personal account," Composites Science and Technology, vol. 68, no. 13, pp. 2585-2591, 2008.

[15] U. Javaid, Z. M. Khan, M. B. Khan, and S. W. ul Hasan, "Fabrication and thermo-mechanical characterization of glass fiber/vinyl ester wind turbine rotor blade," Composites Part B: Engineering, vol. 91, pp. 257-266, 2016.

[16] R. H. Barnes and E. V. Morozov, "Structural optimization of composite wind turbine blade structures with variations of internal geometry configuration," Composite Structures, vol. 152, pp. 158-167, 2016.

[17] M. Tarfaoui, M. Nachtane, H. Khadimallah, and D. Saifaoui, "Simulation of mechanical behavior and damage of large composite wind turbine blade under critical loads," Applied Composite Materials, vol. 25, no. 2, pp. 237-254, 2018.

[18] J. Yang, C. Peng, J. Xiao et al., "Structural investigation of composite wind turbine blade considering structural collapse in full-scale static tests," Composite Structures, vol. 97, pp. 15-29, 2013.
[19] A. Chehouri, R. Younes, A. Ilinca, and J. Perron, "Review of performance optimization techniques applied to wind turbines," Applied Energy, vol. 142, pp. 361-388, 2015.

[20] L. Mishnaevsky and P. Brondsted, "Statically modelling of compression and fatigue damage unidirectional fiber reinforced composites," Composites Science Technology, vol. 69, no. 3-4, pp. 447-484, 2009.

[21] D. Fecko, "High strength glass reinforcemesnts still being discovered," Reinforced Plastics, vol. 50, no. 4, pp. 40-44, 2006.

[22] J. A. Grande, "Wind power blades energize composites manufacturing," Plastics Technology, vol. 54, pp. 68-75, 2008.

[23] F. Reux, "Worldwide composites market: main trends of the composites industry," in Proceedings of the Fifth Innovative Composites Summit-JEC Asia 2012, Singapore, July 2012.

[24] P. Bronds, H. Lilhopt, and A. Lystrup, "Composite materials for wind power turbine blades," Annual Review of Materials Research, vol. 35, no. 1, pp. 505-538, 2005.

[25] J.-M. Park, W.-G. Shin, and D.-J. Yoon, "A study of interfacial aspects of epoxy-based composites reinforced with dual basalt and $\mathrm{SiC}$ fibres by means of the fragmentation and acoustic emission techniques," Composites Science and Technology, vol. 59, no. 3, pp. 355-370, 1999.

[26] N. M. Chikhradze, F. D. S. Marquis, L. A. Japaridze, G. S. Abashidze, and L. M. Okujava, "Polymer based composite and hybrid materials for wind power generation," Materials Science Forum, vol. 654-656, pp. 2612-2615, 2010.

[27] N. Chikhradze, L. Japaridze, and G. Abashidze, "Properties of basalt plastic and of composites reinforced by hybrid fibers in operating conditions," in Composites and Their Applications, pp. 221-246, InTech, London, UK, 2012.

[28] V. Fiore, T. Scalici, G. Di Bella, and A. Valenza, "A review on basalt fibre and its composites," Composites Part B: Engineering, vol. 74, pp. 74-94, 2015.

[29] V. Lopresto, C. Leone, and I. D. Iorio, "Mechanical characterization of basalt fiber reinforced plastic," Composites Part B: Engineering, vol. 42, no. 4, pp. 717-723, 2011.

[30] F. Sarasini, J. Tirillò, M. Valente et al., "Effect of basalt fiber hybridization on the impact behavior under low impact velocity of glass/basalt woven fabric/epoxy resin composites," Composites Part A: Applied Science and Manufacturing, vol. 47, pp. 109-123, 2013.

[31] D. Shah, P. Schubel, and M. Clifford, "Can flax replace E-glass in structural composites? A small wind turbine blade case study," Composites Part B: Engineering, vol. 52, pp. 171-181, 2013.

[32] D. Gay, Composites Materials Design and Applications, CRC Press, Boca Raton, FL, USA, 2014.

[33] ASTM D-3039, Standard Test Method for Tensile Properties of Polymer Matrix Composite Materials, ASTM International, West Conshohocken, PA, USA, 2017.

[34] ASTM D-695-02, Standard Test Method for Compressive Properties of Rigid Plastics, ASTM International, West Conshohocken, PA, USA, 2002.

[35] ASTM D-790-03, Flexural Properties of Unreinforced and Reinforced Plastics and Electrical Insulating Materials, ASTM International, West Conshohocken, PA, USA, 2003.

[36] ASTM D-2344, Standard Test Method for Short-Beam Strength of Polymer Matrix Composite Materials and their laminates, ASTM International, West Conshohocken, PA, USA, 2016.

[37] D. Wood, Small Wind Turbines Analysis, Design and Applications. Green Energy and Technology, Springer, Berlin, Germany, 2011.

[38] S. Rehman, Md. Mahbub Alam, L. M. Alhems, and M. Mujahid Rafique, "Horizontal axis wind turbine blade 
design methodologies for efficiency enhancement-A Review," Energies, vol. 11, no. 3, p. 506, 2018.

[39] M. Tarfaoui, J. Y. Pradillon, and O. R. Shah, "Numerical investigation of a large composite wind turbine with different spar profiles using finite-element method," La Houille Blanche, no. 5, pp. 29-35, 2015.

[40] T. Mostapha, H. Khadimallah, I. Abdellatif, and J. Y. Pradillon, "Design and finite element modal analysis of $48 \mathrm{~m}$ composite wind turbine blade," Applied Mechanics and Materials, vol. 146, pp. 170-184, 2011. 


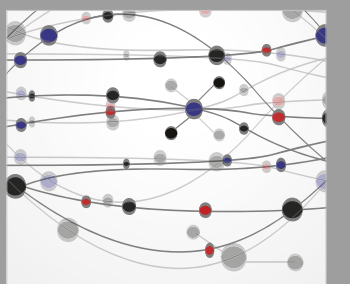

The Scientific World Journal
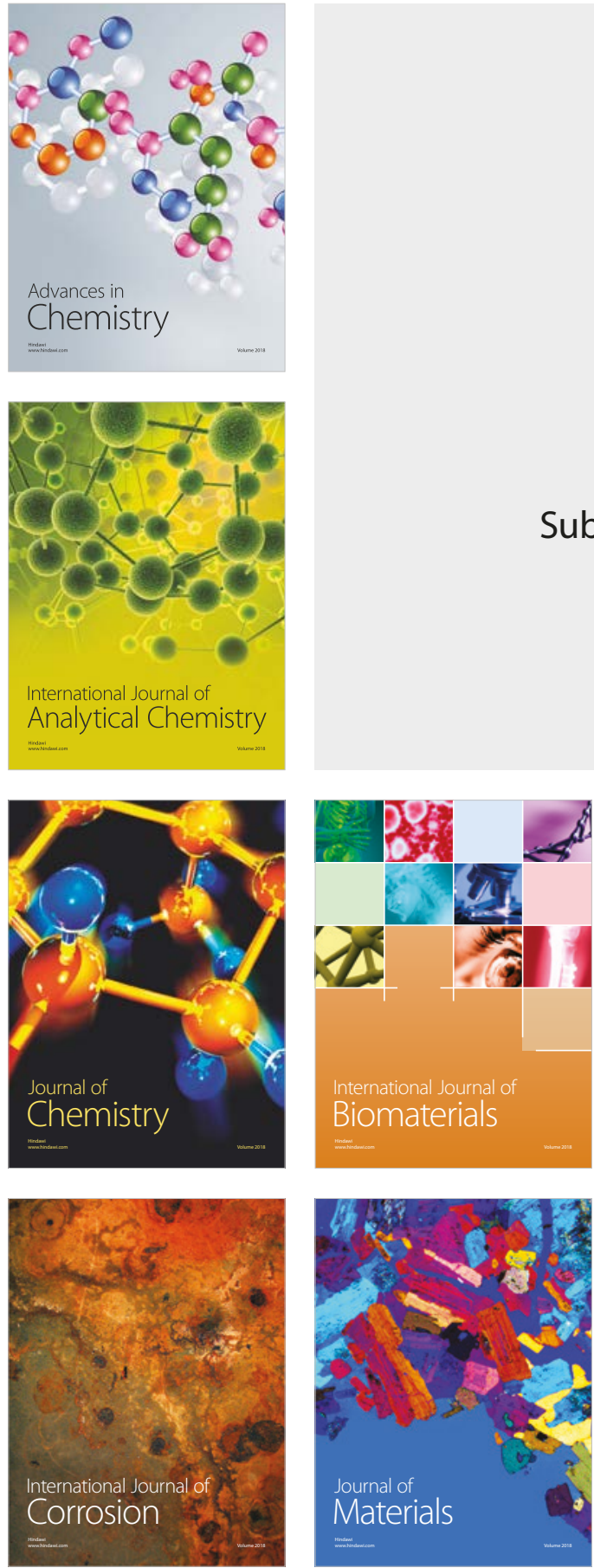

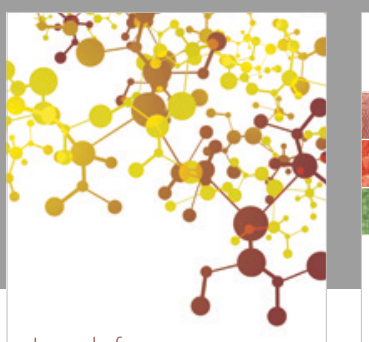

Journal of

Applied Chemistry
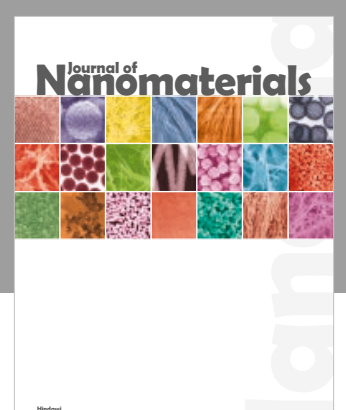

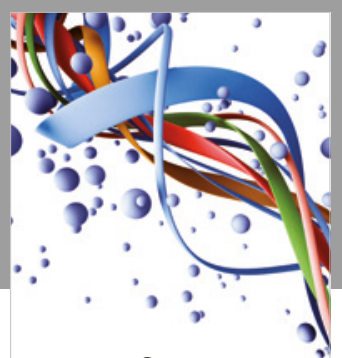

Scientifica

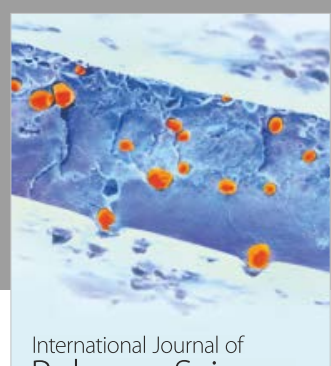

Polymer Science

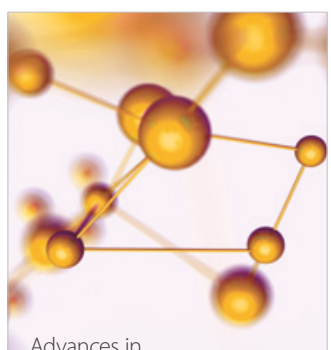

Physical Chemistry
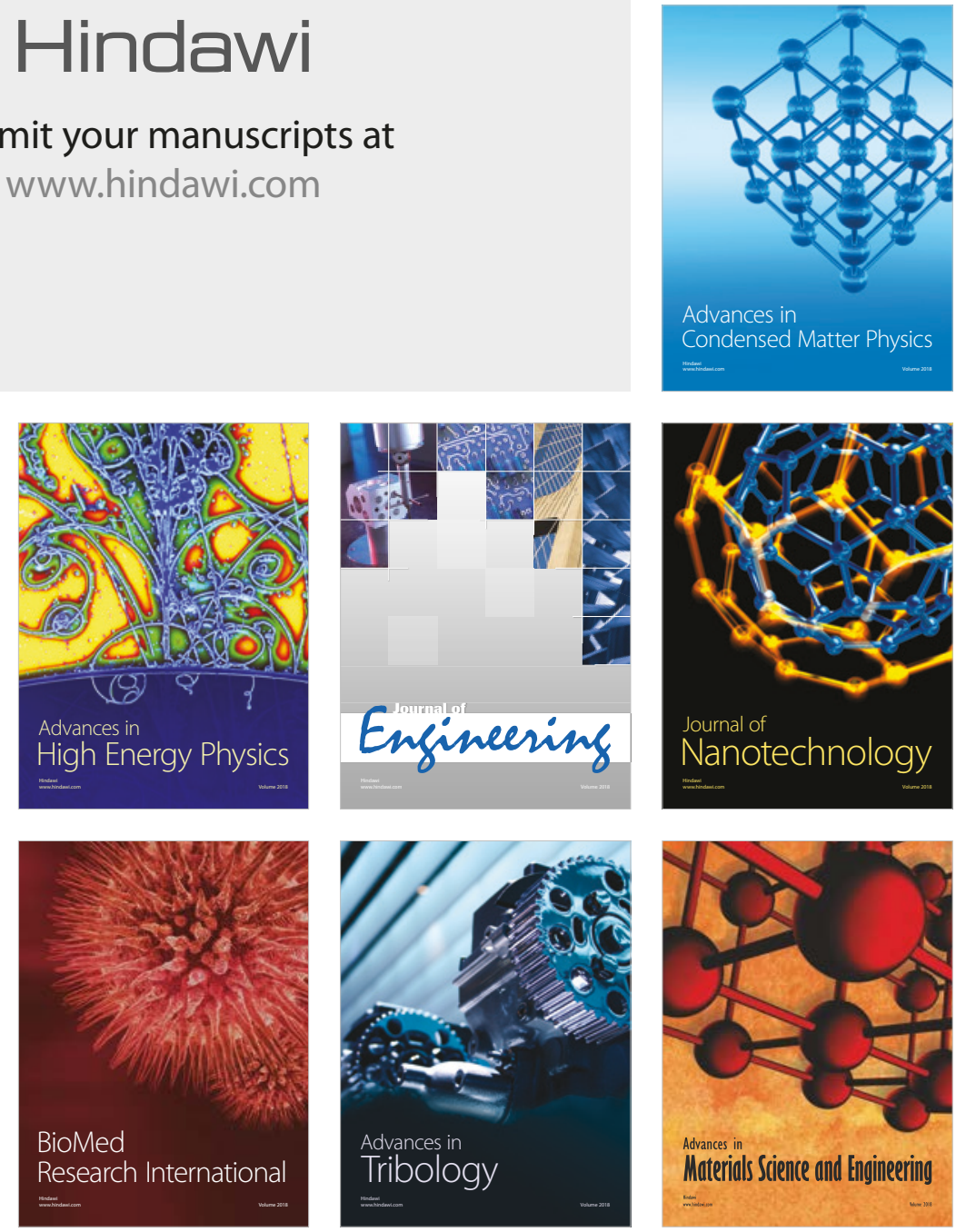